\title{
Omalizumab provides long-term control in patients with moderate-to-severe allergic asthma
}

\author{
R. Buhl*, M. Solèr ${ }^{\#}$, J. Matz ${ }^{\ddagger}$, R. Townley ${ }^{+}$, J. O’Brien ${ }^{\S}$, O. Noga ${ }^{f}$, K. Champain**, H. Fox**, \\ J. Thirlwell**, G. Della Cioppa**
}

Omalizumab provides long-term control in patients with moderate-to-severe allergic asthma. R. Buhl, M. Solèr, J. Matz, R. Townley, J. O'Brien, O. Noga, K. Champain, H. Fox, J. Thirlwell, G. Della Cioppa. C ERS Journals Ltd 2002.

ABSTRACT: The ability of omalizumab, an anti-immnoglobulin- $E$ agent, to maintain long-term disease control in patients with moderate-to-severe allergic asthma was investigated in a 24-week double-blind extension to a 28 -week core trial.

During the extension, 483 of the initial 546 patients were maintained on randomised treatment and the lowest sustainable dose of beclomethasone dipropionate (BDP) as established during the steroid-reduction phase of the core trial. The use of concomitant asthma medication was permitted and investigators were allowed to adjust the BDP dose or switch patients from BDP to other asthma medications if deemed necessary.

More omalizumab-treated patients $(33.5 \%)$ than placebo-treated patients $(13.5 \%)$ were able to complete the extension period without requiring inhaled corticosteroid treatment. The mean BDP equivalent dose throughout the extension was lower in the omalizumab group $\left(25 \mu \mathrm{g} \cdot \mathrm{day}^{-1}\right)$ than in the placebo group $\left(43 \mu \mathrm{g} \cdot \mathrm{day}^{-1}\right)$. Disease control was sustained in $76 \%$ of omalizumab patients compared with $59.4 \%$ of placebo patients free from an asthma exacerbation during the extension period. Compared with placebo, fewer patients in the omalizumab group used other concomitant asthma medication during the extension. Treatment with omalizumab was well tolerated and the incidence of adverse events was similar between groups.

In conclusion, these results suggest that omalizumab is a promising new agent for the long-term control of allergic asthma.

Eur Respir J 2002; 20: 73-78.

\begin{abstract}
*Pulmonary Division, University Hospital, Mainz, Germany. "Pulmonary Division, University Hospital, Basel, Switzerland. Atlantic Asthma and Allergy Centre Inc., Baltimore, MD and ${ }^{+}$Creighton University School of Medicine, Omaha, NE, USA. ${ }^{8}$ City Park Medical Centre, Capetown, South Africa. ${ }^{f}$ Allergy and Asthma Clinic Charité, Berlin, Germany. **Novartis Horsham Research Centre, Horsham, UK.
\end{abstract}

Correspondence: R. Buhl, Pulmonary Division, Mainz University Hospital, Langenbeckstrasse 1, D-55131 Mainz, Germany.

Fax: 496131175545

E-mail: R.Buhl@3-med.klinik. uni-mainz.de

Keywords: Allergic asthma, antiimmunoglobulin-E antibody, omalizu$\mathrm{mab}$

Received: September 62001

Accepted after revision: February 8 2002

This study was supported by Novartis Pharma AG, Basel, Switzerland and Genentech Inc., South San Francisco, CA, USA.
Current asthma management guidelines stress the importance of combined pharmacotherapy to control the underlying inflammatory disease (e.g. with inhaled corticosteroids) and relieve acute symptoms (e.g. with short-acting inhaled $\beta_{2}$-agonists) $[1,2]$. However, some patients remain symptomatic despite high-dose inhaled corticosteroids and suffer from frequent exacerbations [3, 4]. Furthermore, the complexity of such regimens, e.g. the use of multiple inhalers with different frequencies of administration, often leads to poor patient compliance, a major obstacle to successful disease control in the long term. As a consequence, the level of asthma control in the great majority of patients falls far short of the goals for long-term asthma management [5].

In recent years it has become increasingly recognised that immunoglobulin (Ig)-E is a crucial mediator of allergic reactions thought to be responsible for the induction and maintenance of chronic airway inflammation and asthma-related symptoms [6].
Patients of all ages with allergic asthma have higherthan-nomal serum IgE levels, which correlate with the heightened bronchoconstrictor response to a variety of stimuli and the occurrence of symptoms [7-9]. In these patients, allergen exposure produces a characteristic cascade of events that is orchestrated by immune effector cells, specifically mast cells, T-lymphocytes and eosinophils [10, 11]. Therefore, targeting factors involved in the allergen-specific response, such as $\operatorname{IgE}$, is a promising basis for the development of new therapeutic agents, for the treatment of asthma.

Omalizumab (Xolair $\mathbb{R}$, Novartis Pharma AG, Basel, Switzerland/Genentech Inc., South San Francisco, CA, USA), a recombinant humanised monoclonal anti-IgE antibody is the first anti-IgE agent to undergo clinical evaluation in the treatment of IgEmediated diseases [12]. Omalizumab stops the allergic cascade by binding to circulating unbound "free" IgE [13]. This leads to a marked decrease in levels of free 
$\operatorname{IgE}$ and a downregulation of cellular $\operatorname{IgE}$ receptors [14]. Single doses of omalizumab rapidly reduce free IgE concentrations by $>95 \%$ in patients with allergic asthma [15-17].

Recently, the present authors reported the results of a 28-week randomised double-blind, placebocontrolled trial in patients with moderate-to-severe allergic asthma not adequately controlled with inhaled corticosteroids. Omalizumab reduced both the incidence and frequency of asthma exacerbations, while simultaneously reducing the requirement for inhaled corticosterolds [18]. Other indicators of asthma control, such as symptom score, the need for rescue medication and lung function, were also improved by omalizumab. Omalizumab was well tolerated with an excellent safety profile.

In the present study, results from a 24-week doubleblind extension to the core study are reported.

\section{Methods}

\section{Study design and patients}

The methodology of the core study has been reported previously [18]. Briefly, a multicentre, randomised, double-blind, placebo-controlled, parallelgroup study was conducted in Europe, South Africa, Australia and the USA. Patients were all symptomatic on entry to the study, despite treatment with inhaled corticosterolds in doses equivalent to $500-1,200 \mu \mathrm{g} \cdot \mathrm{day}^{-1}$ of beclomethasone dipropionate (BDP).

During a 4-6 week run-in period, all patients were switched to receive treatment with the inhaled corticosterold BDP at the minimum dose required to achieve sustainable symptom control. Following run-in, patients were randomised to receive either omalizumab or placebo administered subcutaneously every 2 or 4 weeks $\left(\geqslant 0.016 \mathrm{mg} \cdot \mathrm{kg}^{-1} \cdot \operatorname{IgE}\right.$ (International Units $\cdot \mathrm{mL}^{-1}$ ) every 4 weeks) for 28 weeks. During the first 16 weeks of treatment, the dose of BDP was maintained at a constant (steroid-stable phase). In the following 12 weeks, the dose of BDP was gradually reduced, where clinically possible, by $25 \%$ of the baseline dose every 2 weeks for 8 weeks, in order to reach a minimum effective dose (steroidreduction phase). The lowest BDP dose required for asthma control was maintained for the remaining 4 weeks of the core study. The use of rescue medication with salbutamol, delivered by a pressurised metereddose inhaler $\left(100 \mu \mathrm{g} \cdot\right.$ puff $\left.^{-1}\right)$, was allowed throughout the study. No other asthma medication was permitted.

The study was conducted in accordance with the Declaration of Helsinki, all patients (or their legal guardian if the patient was $<18$ yrs old) having provided written consent prior to the conduct of study procedures. Ethical approval was obtained from the relevant institutional review board of each study centre.

The core study was followed by a 24 -week doubleblind extension during which patients continued on randomised treatment and the lowest effective dose of BDP (which could be adjusted accordingly). During the extension phase, the use of concomitant asthma medication was liberalised and investigators were allowed to administer additional asthma medication and/or switch patients to other asthma medications if deemed necessary.

\section{Outcome measures}

During the extension, asthma exacerbations, forced expiratory volume in one second (FEV1), BDP use and concomitant asthma medication use were assessed.

An exacerbation was defined as worsening of asthma requiring treatment with oral or parenteral corticosteroids or doubling of the patient's most recent BDP maintenance dose.

Because patients were permitted to change from BDP to other inhaled corticosteroids during the extension, an equivalence table based on the National Institutes of Health Guidelines for the Diagnosis and Management of Asthma was produced so that corticosteroid use could be expressed as "BDP equivalents" (table 1). This equivalence table was also used to determine the BDP dose administered during the run-in period of the core study when patients were switched from their regular inhaled corticosterold.

Spirometry was performed at each visit. Patients were requested to refrain from taking any reliever medication during the $6 \mathrm{~h}$ prior to lung function testing at the clinic. After a 15 min rest, patients performed at least three forced expiratory manoeuvers. The highest of the three FEV1, values obtained were recorded at each visit. Lung function testing was performed prior to administration of the study drug.

The long-term safety and tolerability profile of omalizumab was evaluated over the entire 52-week study. Details of adverse events were collected every 2-4 weeks during the study on a form that recorded all events, irrespective of suspected relationships to the study drug and of mild, moderate or serious severity. Anti-omalizumab antibody levels (Fab) were measured by solid-phase enzyme-linked immunosorbent assay [19].

\section{Statistical analysis}

Statistical analyses were performed using data from all patients entering the extension phase.

Table 1.-Conversion of inhaled corticosteroid dose to beclomethasone dipropionate (BDP) equivalent dose ${ }^{\#}$

Drug Dose

Fluticasone propionate

Triamcinolone acetonide

Budesonide Turbuhaler

Budesonide Turbuhaler

Budesonide MDI

Flunisolide

1 puff $\left(50 \mu \mathrm{g} \cdot\right.$ puff $\left.^{-1}\right)$

2 puffs $\left(100 \mu \mathrm{g} \cdot\right.$ puff $\left.^{-1}\right)$

0.25 puffs $\left(200 \mu \mathrm{g} \cdot\right.$ puff $\left.^{-1}\right)$

0.5 puffs $\left(100 \mu \mathrm{g} \cdot\right.$ puff $\left.^{-1}\right)$

1 puff $\left(100 \mu \mathrm{g} \cdot\right.$ puff $\left.^{-1}\right)$

1 puff $\left(250 \mu \mathrm{g} \cdot\right.$ puff $\left.^{-1}\right)$

MDI: metered dose inhaler. ${ }^{\#}$ : comparable to 1 puff BDP $\left(100 \mu \mathrm{g} \cdot\right.$ puff $^{-1}=$ valve dose $)$. 
The number of asthma exacerbations per patient and the number of patients experiencing at least one asthma exacerbation were analysed using the generalised Cochran-Mantel-Haenszel test (van Elteren test), stratified by dosing schedule ( 2 or 4 weekly dosings). An adjustment was made for patients who discontinued prematurely during the extension phase, adding one exacerbation for every 2 weeks of missed extension phase to any observed exacerbation count in that phase. Asthma exacerbations were not counted as adverse events unless they were serious (e.g. resulted in hospitalisation). This study was powered to show a between treatment difference in the number of asthma exacerbations in the core phase [18].

BDP dose, expressed as percentage of baseline of core study dose, was analysed at 4-weekly intervals during the extension phase using the Wilcoxon-rank sum test. The percentage of patients with no inhaled corticosterold use during the extension and the percentage of patients with $\geqslant 50 \%$ reduction from baseline in their inhaled corticosteroid dose throughout the extension phase were analysed using the generalised Cochran-Mantel-Haenszel test stratified by dosing schedule.

FEV1 was analysed using an analysis of covariance model, fitting centre, sex, treatment schedule and treatment as factors and baseline as a covariate.

The incidence of adverse events was examined using the generalised Cochran-Mantel-Haenszel test stratified by dosing schedule.

Statistical significance was accepted as $\mathrm{p}<0.05$ (two-sided). All analyses of efficacy parameters in the extension were performed post hoc.

\section{Results}

\section{Patients}

A total of 483 (254 omalizumab, 229 placebo) out of the $546(88 \%)$ patients randomised to the core study entered the 24-week double-blind extension.

Nearly three-times as many patients in the placebo group $(26,11.4 \%)$ as in the omalizumab group (10, $3.9 \%$ ) discontinued prematurely during the extension. Withdrawal of consent and loss to follow-up were the most frequent causes of premature termination, affecting more placebo than omalizumab patients in both cases. Two omalizumab patients discontinued due to adverse events. The adverse events causing discontinuation were prostate cancer and "severe dryness of eyes, mouth and sinuses". This second case was investigated extensively and it transpired that the symptoms had been present for $1 \mathrm{yr}$ prior to commencement of the study. Neither event was considered by the investigators to be related to the study drug.

A summary of patient demographics and baseline characteristics is reported in table 2 .

\section{Asthma exacerbations}

As in the core study, the number of asthma exacerbations per patient during the extension phase was
Table 2. - Summary of demographic and baseline ${ }^{\#}$ characteristics (all extension patients)

\begin{tabular}{|c|c|c|}
\hline & Omalizumab & Placebo \\
\hline Subjects & 254 & 229 \\
\hline Sex M:F n & $130: 124$ & 109:120 \\
\hline Race caucasian:other $\mathrm{n}$ & $239: 15$ & $203: 26$ \\
\hline Age yrs & $41(12-76)$ & $40(13-72)$ \\
\hline Duration of asthma yrs & $21(2-68)$ & $19(1-63)$ \\
\hline \multicolumn{3}{|l|}{ Smoking status n (\%) } \\
\hline Nonsmoker & 197 (77.6) & $175(76.4)$ \\
\hline Exsmoker & $57(22.4)$ & $54(23.6)$ \\
\hline Daily BDP dose $\mu \mathrm{g}$ & $766.1(500-1600)$ & $777.3(400-1800)$ \\
\hline $\begin{array}{l}\text { Serum total } \\
\quad \mathrm{IgE} \mathrm{IU} \cdot \mathrm{mL}^{-1}\end{array}$ & $220.2(21-785)$ & $204.1(25-814)$ \\
\hline FEV $1 \%$ pred & $70.0(32-112)$ & $70.4(22-109)$ \\
\hline FEV 1 reversibility $\%$ & $26.3(10-86)$ & $25.7(12-103)$ \\
\hline \multicolumn{3}{|l|}{ Asthma severity ${ }^{+} \mathrm{n}(\%)$} \\
\hline Moderate & 197 (77.6) & $176(76.9)$ \\
\hline Severe & $57(22.4)$ & $53(23.1)$ \\
\hline
\end{tabular}

Data are presented as mean (range) unless otherwise stated. M: male; F: female; BDP: beclomethasone dipropionate; IgE: immunoglobulin-E; IU: International Units; FEV1: forced expiratory volume in one second. ${ }^{\#}$ : baseline of core study; ${ }^{\circ} \%$ increase in FEV1 from baseline within 30 min of taking $200 \mu \mathrm{g}$ salbutamol; ${ }^{+}$: severe=baseline FEV1 $\leqslant 65 \%$ pred and a mean total symptom score of $>4$ out of 9 for the last 14 days of the run-in period.

significantly lower in the omalizumab group compared with the placebo group $(\mathrm{p}<0.001)$ (table 3$)$. The percentage of patients experiencing at least one exacerbation was also significantly lower in omalizumabtreated patients compared with placebo $(\mathrm{p}<0.001)$ (table 3).

\section{Beclomethasone dipropionate dose}

During the extension, patients treated with omalizumab were able to maintain a significantly lower intake of inhaled corticosteroids compared with placebo $(p<0.001)$ (fig. 1$)$. The mean BDP equivalent dose during the extension was $253 \mu \mathrm{g} \cdot \mathrm{day}^{-1}$ in the omalizumab group compared with $434 \mu \mathrm{g} \cdot \mathrm{day}^{-1}$ in the placebo group.

A significantly greater proportion of omalizumab recipients completed the 24-week extension without requiring any inhaled corticosteroid treatment compared with placebo (fig. 2). Furthermore, more than

Table 3. - Asthma exacerbations during the extension (all extension patients)

\begin{tabular}{lcc}
\hline & Omalizumab & Placebo \\
\hline $\begin{array}{l}\text { Subjects n } \\
\text { Mean number of } \\
\text { exacerbations per } \\
\text { patient n (95\% CI) }\end{array}$ & $0.48(0.30-0.66)$ & $1.14(0.81-1.46)^{* * *}$ \\
$\begin{array}{l}\text { Patients with one } \\
\quad \text { or more asthma } \\
\text { exacerbations n (\%) }\end{array}$ & $61(24)$ & $93(40.6)^{* * *}$ \\
\hline
\end{tabular}

Data were analysed using the generalised Cochran-MantelHaenszel test. CI: confidence internal. ${ }^{* * *}: \mathrm{p}<0.001$. 


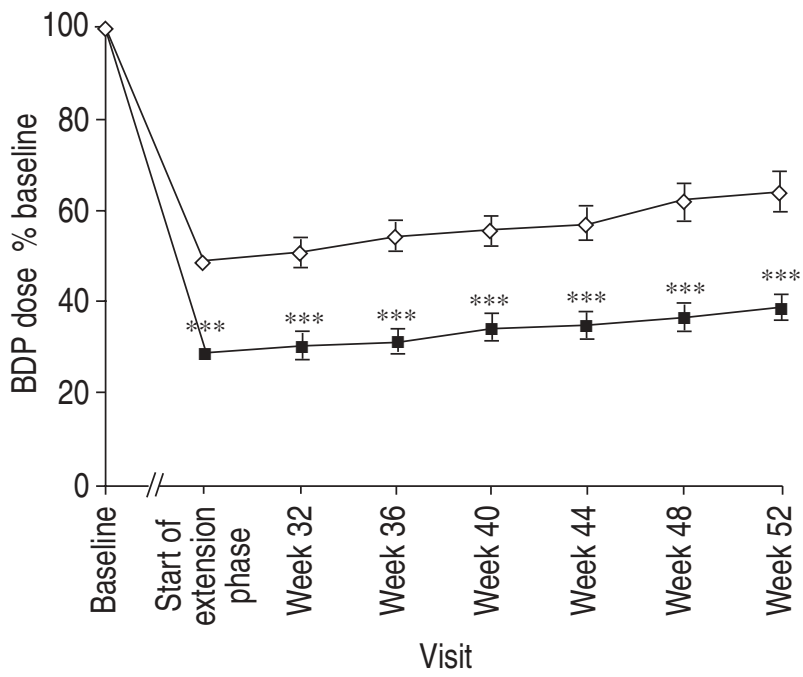

Fig. 1.-Equivalent dose of beclomethasone dipropionate (BDP) expressed as a percentage of baseline. Data are presented as mean \pm SEM. $\mathbf{\square}$ : omalizumab; $\diamond$ placebo. $* * *$ : $\mathrm{p}<0.001$ versus placebo.

half of the omalizumab-treated patients participated in the extension using $\leqslant 50 \%$ of a BDP equivalent dose of inhaled corticosteroid relative to baseline (i.e. start of core phase) versus approximately one-third of placebo recipients (fig. 2).

\section{Concomitant asthma medication use}

During the 24-week extension, the rise of concomitant asthma medication was lower in the omalizumab group than in the placebo group (table 4).

\section{Forced expiratory volume in one second}

No statistically significant differences in FEV1 were seen between the treatment groups at any time point during the extension phase.

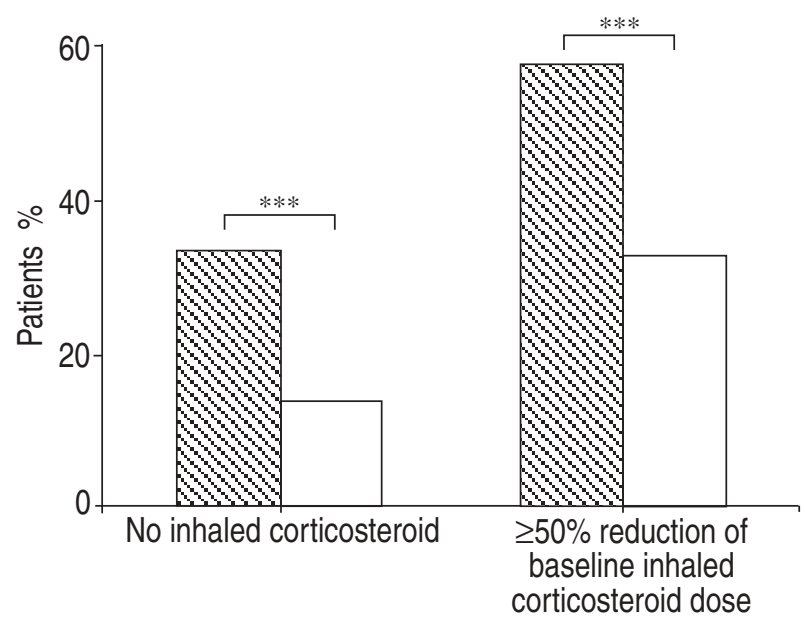

Fig. 2.-Percentage of patients who completed the extension with no usage of inhaled corticosteroid during the extension phase, and those with $a \geqslant 50 \%$ reduction of baseline dose throughout the extension. $\mathbb{\mathbb { * }}$ : omalizumab $\mathrm{n}=254 ; \square$ placebo $\mathrm{n}=229$. $* * *: \mathrm{p}<0.001$.
Table 4.-Percentage of patients receiving concomitant asthma medications by drug class (all extension patients)

\begin{tabular}{lcc}
\hline Drug class & Omalizumab & Placebo \\
\hline Subjects n & 254 & 229 \\
Inhaled corticosteroids & 64.6 & 84.7 \\
$\quad$ Fluticasone propionate & 0.8 & 2.2 \\
$\quad$ Budesonide & 0.0 & 1.3 \\
Long acting $\beta_{2}$-agonists & 11.0 & 17.0 \\
$\quad$ Salmeterol hydroxynaphthoate & 5.9 & 11.4 \\
$\quad$ Formoterol fumarate & 4.7 & 5.7 \\
Leukotriene inhibitors & 0.4 & 3.5 \\
$\quad$ and antagonists & & \\
Xanthines & 0.4 & 0.0 \\
\hline
\end{tabular}

Data are presented as $\%$. ${ }^{\#}$ : formoterol not marketed in USA.

\section{Safety and tolerability}

As in the core study [18], treatment with omalizumab was well tolerated. The overall incidence of adverse events was comparable between the treatment groups during the 24-week extension $(\mathrm{p}=0.548)$ and for the entire 52-week study period $(\mathrm{p}=0.579)$ (table 5). Although a slightly higher incidence of adverse events affecting the digestive system (including nausea, gastroenteritis, diarrhoea, abdominal pain, dyspepsia and toothache) was detected in the omalizumab group (affecting $32 \%$ of omalizumab patients versus $25 \%$ of placebo patients over the 52-week period), there was no particular adverse event which was common to either group.

Nine $(3.5 \%)$ patients on omalizumab and $10(4.4 \%)$ patients on placebo had serious adverse events during the extension. These included four patients $(1.7 \%)$ on placebo compared with one $(0.4 \%)$ patient on omalizumab who experienced asthma exacerbations resulting in hospitalisation.

There were no adverse events suggestive of immunological reactions during the 24-week extension. Local injection-site symptoms were associated with $5.3 \%$ of omalizumab injections and $4.3 \%$ of placebo injections, the majority of which were mild-tomoderate in severity.

No patient on omalizumab developed antiomalizumab antibodies.

\section{Discussion}

Anti-inflammatory agents are considered to be the cornerstone of therapy for patients with persistent asthma [1]. However, current asthma therapies are aimed at reducing inflammation and symptoms only after the allergic process has begun. As IgE is an early and central factor responsible for the induction and progression of allergic reactions, it is a promising target in the treatment of asthma. A clear advantage of blocking $\mathrm{IgE}$ is that the allergic cascade is interrupted at the initiation stage prior to mediator release.

Omalizumab, a recombinant humanised monoclonal anti-IgE antibody is the first anti-IgE agent to undergo clinical evaluation in the treatment of allergic 
Table 5. - Patients with adverse events $(A E)$ in most frequently affected body systems ( $\geqslant 5 \%$ in either group)

\begin{tabular}{|c|c|c|c|c|}
\hline & \multicolumn{2}{|c|}{$\begin{array}{l}\text { 24-week double-blind extension } \\
\text { (all extension patients) }\end{array}$} & \multicolumn{2}{|c|}{$\begin{array}{l}\text { 52-week overall safety } \\
\text { (all randomised patients) }\end{array}$} \\
\hline & Omalizumab & Placebo & Omalizumab & Placebo \\
\hline Total patients studied & $254(100)$ & $229(100)$ & $274(100)$ & $272(100)$ \\
\hline Total patients with an AE & $161(63.4)$ & $151(65.9)$ & $229(83.6)$ & $232(85.3)$ \\
\hline \multicolumn{5}{|l|}{ Body system affected } \\
\hline Respiratory & $84(33.1)$ & $97(42.4)$ & $160(58.4)$ & $173(63.6)$ \\
\hline Infections and infestations & 49 (19.3) & $53(23.1)$ & $124(45.3)$ & $132(48.5)$ \\
\hline Nervous & $40(15.7)$ & $40(17.5)$ & $99(36.1)$ & $90(33.1)$ \\
\hline Musculoskeletal & $40(15.7)$ & $27(11.8)$ & $86(31.4)$ & $78(28.7)$ \\
\hline Body as a whole & $35(13.8)$ & $36(15.7)$ & $78(28.5)$ & $81(29.8)$ \\
\hline Digestive & $33(13.0)$ & $22(9.6)$ & $88(32.1)$ & $69(25.4)$ \\
\hline Skin and appendages & $22(8.7)$ & $17(7.4)$ & $46(16.8)$ & $44(16.2)$ \\
\hline Special senses & $12(4.7)$ & $13(5.7)$ & $35(12.8)$ & $26(9.6)$ \\
\hline Urogenital and reproductive & $16(6.3)$ & $19(8.3)$ & $36(13.1)$ & $33(12.1)$ \\
\hline Cardiovascular & $2(0.8)$ & $3(1.3)$ & $13(4.7)$ & $17(6.3)$ \\
\hline
\end{tabular}

Data are presented as n (\%).

asthma. The present authors have reported previously that 28 weeks of treatment with omalizumab simultaneously reduces both asthma exacerbations and corticosteroid requirement, while improving other parameters of disease control in patients with moderate-to-severe allergic asthma [18]. The results of this 24-week double-blind extension show that omalizumab continues to reduce the frequency and incidence of asthma exacerbations while allowing sustained reduction in the need for inhaled corticosteroids and other concomitant asthma medication.

Analysis of asthma exacerbations during the extension phase revealed that, compared with placebo, significantly fewer omalizumab patients experienced an asthma exacerbation. The mean number of exacerbations per patient was also significantly lower in favour of omalizumab. This is entirely consistent with observations during the core study [18] and was achieved even though patients on omalizumab maintained a lower dose of inhaled corticosteroids and used fewer other concomitant asthma medications. The tendency towards more frequent discontinuations in the placebo group observed in the core phase [18] persisted in the extension, with $26(11.4 \%)$ placebo patients discontinuing prematurely from the extension compared with $10(3.9 \%)$ omalizumab patients. This imbalance probably reflects the patients' overall satisfaction with treatment.

During the extension, significantly more patients on omalizumab $(57 \%)$ were able to reduce their inhaled corticosteroid dose by $\geqslant 50 \%$ compared with those on placebo $(32 \%)$, and sustain this reduced dose throughout the extension. The fact that there was a slight increase in the dose of inhaled corticosteroids in both treatment groups during the course of the extension (fig. 1) may reflect the fact that changes in BDP dose and the use of other inhaled corticosterolds were not discouraged during this phase.

It is well established that asthma control improves considerably in a clinical-trial setting, even for patients on placebo treatment. One possible explanation for this is improved compliance because of close monitoring by an investigator and repeated encouragement to adhere to therapeutic regimens. Compliance among asthma patients requiring long-term treatment is often poor, particularly for those requiring inhaled corticosteroids. In a recent survey among European patients with moderate and severe persistent asthma, the most disturbing finding was the high level use of as-required bronchodilator medications and the low level use of anti-inflammatory medications [5]. It is possible that new types of asthma medications such as omalizumab, which considerably reduce dependence on inhaled corticosteroids and require much less frequent administration, will improve asthma control by improving compliance and facilitating long-term treatment.

There were no significant differences in FEV1 between the treatment groups during the extension phase. This result is not unexpected. Patients were permitted to use concomitant asthma medication throughout the extension phase and the placebotreated patients used more asthma medication than the omalizumab-treated patients (table 4). In particular, the use of bronchodilators could potentially confound spirometric values in this phase of the study. The addition of an anti-inflammatory agent that does not possess acute bronchodilator properties would not, therefore, be expected to provide further large improvements in FEV1.

As demonstrated in other studies [19], the safety profile of omalizumab was reassuring, and treatment was well tolerated over the entire 52-week treatment period.

In conclusion, the results of this study indicate that omalizumab is effective in the long-term control of patients with allergic asthma, controlling disease while reducing corticosteroid requirement. Such findings indicate that omalizumab is a promising new agent for the treatment of allergic asthma. It may be particularly useful in patients suffering from persistent symptoms even with conventional treatment. The dosing schedule may greatly enhance compliance in allergic asthma patients requiring complex therapeutic regimens. In addition, as omalizumab is effective in the management of allergic rhinitis [19], it may benefit 
patients with concomitant lung, nose and eye symptoms.

Acknowledgements. The authors would like to thank the following investigators, listed by country, for contributing patient data. Australia: R. Ruffin, R. Scicchitano; Austria: G. Kalk; Germany: C. Kroegel, K-C Bergmann, H. Leiner; Italy: G.W. Canonica, G. D'Amato, G. Moscato, E. Marchi; the Netherlands: R. Aalbers, J.P.H.M. Creemers, E.F. Dubois, A. Greefhorst, P.B. Luursema, A. Sips; South Africa: A.P. Foden, J. Terblanche; UK: A. Millar, M. Spiteri, A. Tattersfield, K.F. Chung; USA: G. Bensch, T. Casale, L. Ford, A Nayak, H. Beede, J. Yarbrough, S. Fineman, N. LaHood, G.G. Shapiro, J. Wolfe, E. Lisberg, T. Lee, A. Martin, H. Windom, B.Q. Lanier, W. Berger.

\section{References}

1. National Asthma Education and Prevention Program Expert Panel. Expert Panel No.2: Guidelines to the Diagnosis and Management of Asthma. NIH Publication No. 97-4051. Bethesda, MD, USA, National Heart and Blood Institute, 1997.

2. British Asthma Guidelines Co-ordinating Committee. British guidelines on asthma management: 1995 review and position statement. Thorax 1997; 52: S1S24.

3. Barnes PJ. Should anti-inflammatory agents be used earlier in asthma? J Respir Dis 1998; 19: S28-S34..

4. Barnes PJ. Current issues for establishing inhaled corticosteroids as the antiinflammatory agents of choice in asthma. J Allergy Clin Immunol 1998; 101: S427-S433.

5. Rabe KF, Vermeire PA, Soriano JB, Maier WC. Clinical management of asthma in 1999: the Asthma Insights and Reality in Europe (AIRE) study. Eur Respir J 2000; 16: 802-807.

6. Lemanske RF Jr, Busse WW. Asthma. JAMA 1997; 278: 1855-1873.

7. Burrows B, Martinez FD, Halonen M, Barbee RA, Cline MG. Association of asthma with serum IgE and skin-test reactivity to allergens. N Engl J Med 1989; 320: 271-277.
8. Sears MR, Burrows B, Flannery EM, Herbison GP, Hewitt CJ, Holdaway MD. Relation between airway responsiveness and serum $\mathrm{IgE}$ in children with asthma and in apparently normal children. $N$ Engl $\mathrm{J} \mathrm{Med}$ 1991; 325: 1067-1071.

9. Sherrill DL, Stein R, Halonen M, Holberg CJ, Wright A, Martinez FD. Total serum IgE and its association with asthma symptoms and allergic sensitization among children. J Allergy Clin Immunol 1999; 104: 28-36.

10. Borish L, Rosenwasser LJ. Update on cytokines. J Allergy Clin Immunol 1996; 97: 719-734.

11. Church MK, Levi-Schaffer F. Updates on cells and cytokines: the human mast cell. J Allergy Clin Immunol 1999; 99: 155-160.

12. Easthope S, Jarvis B. Omalizumab. Drugs 2001; 61: 253-260.

13. Presta L, Shields R, O'Connell L, et al. The binding site on human immunoglobulin $\mathrm{E}$ for its high affinity receptor. J Biol Chem 1994; 269: 26368-26373.

14. MacGlashan DW Jr, Bochner BS, Adelman DC, et al. Down-regulation of FceRI expression on human basophils during in vivo treatment of atopic patients with anti-IgE antibody. J Immunol 1997; 158: 1438 1445.

15. Boulet LP, Chapman KR, Cote J, et al. Inhibitory effects of an anti-IgE antibody E25 on allergeninduced early asthmatic response. Am J Respir Crit Care Med 1997; 155: 1835-1840.

16. Corne J, Djukanovic R, Thomas L, et al. The effect of intravenous administration of a chimeric anti- $\operatorname{IgE}$ antibody on serum IgE levels in atopic subjects: efficacy, safety, and pharmacokinetics. J Clin Invest 1997; 99: 879-887.

17. Fahy JV, Fleming HE, Wong $\mathrm{HH}$, et al. The effect of an anti-IgE monoclonal antibody on the earlyand late-phase responses to allergen inhalation in asthmatic subjects. Am J Respir Crit Care Med 1997; 155: $1828-1834$.

18. Solèr $\mathrm{M}$, Matz $\mathrm{J}$, Townley $\mathrm{R}$, et al. The anti-IgE antibody omalizumab reduces exacerbations and steroid requirement in allergic asthmatics. Eur Respir $J$ 2001; 18: 254-261.

19. Ädelroth E, Rak S, Haahtela T, et al. Recombinant humanized mAb-E25, an anti-IgE $\mathrm{mAb}$, in birch pollen-induced seasonal allergic rhinitis. $J$ Allergy Clin Immunol 2000; 106: 253-259. 